\title{
With a letter-searched prime, boat primes float but swim and coat don't: Further evidence for automatic semantic activation
}

\author{
Matthew J. Pastizzo \\ State University of New York, College at Geneseo, Geneseo, New York \\ JAMES H. NeELY \\ State University of New York, University at Albany, Albany, New York \\ AND \\ ChI-Shing Tse \\ Washington University, St. Louis, Missouri
}

\begin{abstract}
Letter search (LS) on the prime typically eliminates semantic priming (swim-float) and orthographic/ phonological $(\mathrm{O} / \mathrm{P})$ priming (coat-float) but not morphological priming (marked-mark). However, LS on the prime does not reduce semantic priming for low-frequency targets (Tse \& Neely, 2007). These findings suggest that semantic activation survives LS but decays during LS to a low level that can be detected only with sensitive measures, which are afforded by low-frequency targets and morphologically related primes and targets. In the present research, we show that LS on the prime results in $0 \mathrm{msec}$ of semantic priming (e.g., swim-float) and $11 \mathrm{msec}$ of $\mathrm{O} / \mathrm{P}$ priming (e.g., coat-float), both of which are statistically null, whereas the LS semantic $+\mathrm{O} / \mathrm{P}$ priming effect for primes and targets that do not share a morpheme (e.g., boat-float) is a robust $37 \mathrm{msec}$. Discussion focuses on the automaticity of semantic activation and whether morphological priming is mediated by (1) a morphemic representation that is separate from semantic representations or (2) activation combined from semantics and orthography/phonology.
\end{abstract}

In various conditions and tasks (see McNamara, 2005), reaction times (RTs) to a target word (e.g., $d o g$ ) are faster when it is preceded by a related prime (e.g., CAT) rather than an unrelated prime (e.g., HIP). However, when a letter search (LS) is conducted on the prime, this semantic priming effect is almost never statistically significant in individual experiments (see Tse \& Neely, 2007, Table 1). This trend led Stolz and Besner (1999) to conclude that automatic/attention-free semantic activation (e.g., Neely, 1977 ) is a myth, because semantic activation requires attentional resources that LS depletes.

Although LS on the prime eliminates semantic and orthographic/phonological $(\mathrm{O} / \mathrm{P})$ priming (Ferguson \& Besner, 2006; Kahan, Sellinger, \& Broman-Fulks, 2006), it does not eliminate morphological (marked-mark) priming (Ferguson \& Besner, 2006; Stolz \& Besner, 1998). One explanation for this (e.g., Brown, Stolz, \& Besner, 2006; Stolz \& Besner, 1998), which we will call the extended morphological/lexical representation hypothesis (hereafter shortened to extended morphological hypothesis), is that morphological priming occurs at a specialized morphological/lexical representational level that is activated independently of semantic and phono- logical representations (a popular view among morphology researchers; e.g., Marslen-Wilson, Tyler, Waksler, \& Older, 1994) and whose activation is unaffected by LS, even though LS eliminates the activation of semantic and O/P representations (i.e., Stolz \& Besner's extension of that hypothesis). Two assumptions are inherent in the extended morphological hypothesis: that semantic activation is not automatic and that morphological priming is attributable to a specialized morphological/lexical representational level.

A partial challenge to the extended morphological hypothesis is Tse and Neely's (2007) finding that, although LS eliminates semantic priming for high-frequency targets, which typically have been used in prior studies, it does not eliminate semantic priming for low-frequency targets. Tse and Neely (see also Neely \& Kahan, 2001) argued that whereas LS may completely shut down strategic priming mechanisms that do require attentional resources (e.g., expectancy and retrospective semantic matching; see Neely \& Keefe, 1989), semantic activation is indeed automatic and unaffected by LS. According to Tse and Neely, during the approximately $1 \mathrm{sec}$ it takes to complete LS, the full-blown semantic activation initially produced

M. J. Pastizzo, pastizzo@geneseo.edu 
by the LS prime decays to a level low enough that it can go undetected. Presumably, the small increment in target activation produced by the related prime (via the small amount of decayed activation remaining after LS) was detectable against the low baseline activation of a lowfrequency target but not against the high baseline activation of a high-frequency target. Although LS semantic priming for low-frequency targets provides direct evidence against the first assumption of Stolz and Besner's (1998) extended morphological hypothesis, it does not address directly whether morphological priming is attributable to independent morphemic representations.

Tse and Neely's (2007) account provides the basis for an alternative explanation of why LS eliminated semantic and $\mathrm{O} / \mathrm{P}$ priming but not morphological priming for Stolz and Besner's (1998) high-frequency targets. According to a summed activation hypothesis, when the separate, undetectable low levels of decayed semantic and $\mathrm{O} / \mathrm{P}$ activation from LS primes are combined, as they are in morphological priming, their summed activation becomes detectable in priming even for high-frequency targets. However, because morphologically related prime-target pairs not only overlap with respect to semantics and $\mathrm{O} / \mathrm{P}$, but also share a morpheme, it is unclear whether the observed morphological priming is due to summed activation from separate semantic and $\mathrm{O} / \mathrm{P}$ representations or to a separate morphemic representation.

To test between the extended morphological hypothesis and the summed activation hypothesis for why LS eliminates both semantic and $\mathrm{O} / \mathrm{P}$ priming but not morphological priming, one must examine LS priming using primetarget pairs that are both semantically and $\mathrm{O} / \mathrm{P}$ related $(\mathrm{Sem}+\mathrm{O} / \mathrm{P})$ but do not share a morpheme (boat-float). Ideally, the same targets should be rotated through all of the priming conditions and the $\mathrm{Sem}+\mathrm{O} / \mathrm{P}$ pairs should match the semantically related (Sem; swim-float) pairs with respect to semantic/associative relations and the $\mathrm{O} / \mathrm{P}$ related (coat-float) pairs with respect to $\mathrm{O} / \mathrm{P}$ overlap. They should also have high-frequency targets as in Stolz and Besner (1998). However, because so few Sem + O/P pairs in English satisfy the first criterion (see Pastizzo, 2003, whose materials we used), we were left with pairs that had targets with much lower word frequencies, with weaker semantic overlap, and with lower associative strengths than those for Stolz and Besner's (1998) primetarget pairs. Although our targets were low in frequency, which could lead to non-null LS semantic priming (Tse \& Neely, 2007), the weaker association strengths and lower semantic relatedness values of our pairs may yield a semantic priming effect that still cannot be detected for semantically related prime-target pairs that are not also $\mathrm{O} / \mathrm{P}$ related. If that were so, our materials would still allow us to test whether semantic activation from an LS prime that is too weak to be detected by itself could be detectable when summated with a null LS O/P priming effect (Ferguson \& Besner, 2006; Kahan et al., 2006).

In summary, if LS on the prime produces null Sem (swim-float) and O/P (coat-float) priming effects due to the low levels of semantic and $\mathrm{O} / \mathrm{P}$ activation from the prime that decayed during LS, the extended morpho- logical hypothesis predicts that $\mathrm{Sem}+\mathrm{O} / \mathrm{P}$ (boat-float) priming should also be null, because the prime and target do not share a morphemic representation. However, according to the summed activation hypothesis, LS might not eliminate boat-float priming, because when the two weak, decayed activation levels in the separate semantic and $\mathrm{O} / \mathrm{P}$ representational systems combine, their summed activation levels could be sufficient to produce significant $\mathrm{Sem}+\mathrm{O} / \mathrm{P}$ priming that is statistically larger than the sum of the individual null Sem and O/P priming effects. ${ }^{1}$ The present experiment tests between these two possibilities.

\section{METHOD}

\section{Participants}

Eighty-two monolingual English speakers with normal or corrected-to-normal vision and no known reading or speech disabilities were recruited from the psychology subject pool at the State University of New York, College at Geneseo, for extra credit.

\section{Materials and Design}

Forty-eight critical target words and their primes were selected from Pastizzo (2003). Four types of primes were created for each target (float): a Sem $+\mathrm{O} / \mathrm{P}$ related prime (boat), a Sem related prime (swim), an $\mathrm{O} / \mathrm{P}$ related prime (coat), and an unrelated (Unrel) prime (seed). To equate perfectly the prime-target $\mathrm{O} / \mathrm{P}$ overlap for the $\mathrm{Sem}+\mathrm{O} / \mathrm{P}$ and the $\mathrm{O} / \mathrm{P}$ conditions, Pastizzo always used rhyming primes and targets in both conditions for a particular target differing in only its first one or two letters. The mean lengths of the four different kinds of primes were closely matched (range $=4.3-4.5$ letters) and equivalent to the mean length of the targets (4.6 letters). $\mathrm{Sem}$ and Sem $+\mathrm{O} / \mathrm{P}$ pairs were well matched with respect to semantic overlap (Landauer \& Dumais, 1997; LSA cosines of 0.33 and 0.25 ) and Nelson, McEvoy, and Schreiber (2004) forward (0.03 and $0.02)$ and backward (0.06 and 0.07$)$ associative strengths. Although these values were low, they were statistically greater than their corresponding values for the unrelated priming condition ( 0.09 LSA cosines, 0.00 forward and 0.00 backward associative strengths) and the $\mathrm{O} / \mathrm{P}$ priming condition $(0.13,0.00$, and 0.00 , respectively). Our Sem prime-target pairs were much less related semantically and much less associated than Tse and Neely's (2007) symmetrically related Sem pairs $(0.44,0.30$, and 0.23 , respectively) and much less related semantically but not less associated than Stolz and Besner's (1998) Sem pairs $(0.54,0.35$, and 0.34 , respectively) and morphologically related pairs $(0.48,0.01$, and 0.00 , respectively). Our targets had relatively low Kučera and Francis (1967) word frequencies of 21 per million that were equivalent to those of Tse and Neely's lowfrequency targets (23 per million) but far lower than those of Stolz and Besner's (1998) targets (105 per million). The four different kinds of primes had statistically equivalent mean word frequencies $($ range $=62-79)$

Across eight counterbalancing lists, each critical target was paired with all four prime types and each prime was paired with both a positive and a negative probe letter. Within lists, each prime type was tested equally often with positive and negative probe letters, and each prime and target appeared once. The same positive and negative probe letters were selected for each prime and were presented to all participants. Positive probe letters were chosen randomly with equal probability from each of the prime's letter positions, and negative probe letters were selected randomly with probabilities matching their probabilities of occurrence in all primes within their counterbalancing list.

To minimize the contribution of strategic priming mechanisms (see Neely, Keefe, \& Ross, 1989), 24 unrelated word-prime/wordtarget pairs were added as fillers to reduce the proportion of related primes and targets. Thus, in each list, there were 72 word-prime/ word-target pairs: $12 \mathrm{Sem}, 12 \mathrm{O} / \mathrm{P}, 12 \mathrm{Sem}+\mathrm{O} / \mathrm{P}$, and 36 Unrel (the 12 critical and 24 filler trials). Seventy-two word-prime/nonword- 
target pairs ( page-milse) were created for the lexical decision task. To mimic word-word pairs, 24 of them were $\mathrm{O} / \mathrm{P}$ related (halt-gralt). The practice trials included 12 word-prime/word-target pairs and 12 word-prime/nonword-target pairs having the same prime-type proportions as in the experimental list. Each participant received a different random ordering of stimuli in the practice and experimental trials. In short, for the word targets we used a 4 (prime type: Unrel, $\mathrm{Sem}, \mathrm{O} / \mathrm{P}, \mathrm{Sem}+\mathrm{O} / \mathrm{P}) \times 2$ (probe letter type: positive, negative) completely randomized within-participants design.

\section{Procedure}

E-Prime 1.1 software was used. Individually tested participants received 24 practice trials, followed by 144 experimental trials. On each trial, participants indicated whether or not the probe letter appeared in the prime and whether the following letter string (i.e., the target) was a correctly spelled English word by pressing the "yes" button with the right index finger or the "no" button with the left index finger on an E-Prime compatible PST serial response box.

On each trial, a "+" fixation point appeared in the center of the screen for $1,000 \mathrm{msec}$ followed by a 50 -msec blank screen. An uppercase probe letter (e.g., A) and an uppercase prime word (e.g., BOAT) then appeared simultaneously and remained on the screen until participants responded in the following format:

\section{AAAA \\ BOAT}

A lowercase target letter string (e.g., float) appeared one line below the prime $200 \mathrm{msec}$ after the LS response, terminating the target's presentation. All stimuli appeared in black Courier New 18-point font on a white screen and were left-justified at the center of the screen. Neither accuracy nor RT feedback was given for either task. The intertrial interval was $750 \mathrm{msec}$. Participants were given a break halfway through the experimental trials.

\section{RESULTS}

Unless specified otherwise, statistical significance is associated with a two-tailed $p<.05$. Data from 2 participants were removed because their mean lexical decision errors were higher than $10 \%$. (However, each counterbalancing list was presented to 10 participants from whom the data are reported.) Only RT data from word-target critical trials for which correct responses were made in both the LS and lexical decision tasks were analyzed, which eliminated data from $3.0 \%$ of the word-target critical trials. Table 1 presents the RT and error data for the various conditions in the LS and lexical decision tasks. Throughout this article, the $\pm X$ following a mean represents the $95 \%$ confidence interval.

\section{LS Task}

LS RTs and errors averaged $1,108 \mathrm{msec}$ and $1.4 \%$. RTs were $167 \pm 36 \mathrm{msec}$ longer but $0.78 \% \pm 0.76 \%$ less error prone for negative than for positive probes, suggesting a speed-accuracy trade-off.

\section{Lexical Decision Task}

The mean RTs and mean percentage errors were analyzed in separate 4 (prime type) $\times 2$ (probe letter type) repeated measures ANOVAs, with participants treated as random effects. ${ }^{2}$ Probe letter type did not produce a main effect for either RTs or errors and did not interact with prime type for either RTs or errors (all $F \mathrm{~s}<1.59$ ). Of central interest, the main effect of prime type was significant for RTs $\left[F(3,237)=6.50, M S_{\mathrm{e}}=7,568\right]$ and errors $\left[F(3,237)=2.85, M S_{\mathrm{e}}=21.41\right]$. As is shown in Table 1, RTs were faster in the Sem $+\mathrm{O} / \mathrm{P}$ priming condition than in the other conditions, which yielded similar RTs. Sem priming for LS primes was nonexistent $(0 \mathrm{msec})$, and the 11 -msec $\mathrm{O} / \mathrm{P}$ priming effect did not approach significance $(p>.25)$. Most important, despite these two null LS priming effects, the $37-\mathrm{msec}$ LS Sem $+\mathrm{O} / \mathrm{P}$ priming effect was robust $(p<.0001)$ and was $26.6 \pm 25.7 \mathrm{msec}$ greater than the 11-msec sum of the individual 0-msec Sem and 11$\mathrm{msec} \mathrm{O} / \mathrm{P}$ priming effects. This significant overadditivity of Sem and $\mathrm{O} / \mathrm{P}$ priming for primes and targets that do not share a morpheme supports the summed activation hypothesis over Stolz and Besner's (1998) extended morphological hypothesis for why LS eliminates Sem priming and $\mathrm{O} / \mathrm{P}$ priming but not morphological priming.

Table 1 also shows that there were fewer errors in the Sem priming and $\mathrm{Sem}+\mathrm{O} / \mathrm{P}$ priming conditions, which yielded comparable error rates, than in the $\mathrm{O} / \mathrm{P}$ and Unrel conditions, which also yielded comparable error rates. The $1.0 \%$ Sem and $0.9 \% \mathrm{Sem}+\mathrm{O} / \mathrm{P}$ priming effects were significant by two- and one-tailed tests, respectively. The finding of a significant Sem priming effect for errors but not for RTs is not unprecedented (e.g., Brown, Roberts, \& Besner, 2001; Chiappe, Smith, \& Besner, 1996).

Table 1

Mean Target Word Reaction Time (RT, in Milliseconds) and Percentage Error (With Standard Deviations) in the Letter Search and Lexical Decision Tasks As a Function of Prime Type

\begin{tabular}{|c|c|c|c|c|c|c|c|c|}
\hline & \multicolumn{8}{|c|}{ Prime Type } \\
\hline & \multicolumn{2}{|c|}{$\begin{array}{c}\text { Unrel } \\
\text { (SEED-float) } \\
\end{array}$} & \multicolumn{2}{|c|}{$\begin{array}{c}\text { Sem } \\
\text { (swIM-float) } \\
\end{array}$} & \multicolumn{2}{|c|}{$\begin{array}{c}\mathrm{O} / \mathrm{P} \\
\text { (COAT-float }) \\
\end{array}$} & \multicolumn{2}{|c|}{$\begin{array}{r}\mathrm{Sem}+\mathrm{O} / \mathrm{P} \\
(\mathrm{BOAT}-\text { float })\end{array}$} \\
\hline & $M$ & $S D$ & $M$ & $S D$ & $M$ & $S D$ & $M$ & $S D$ \\
\hline Letter search RT & 1,124 & 246 & 1,106 & 226 & 1,099 & 229 & 1,109 & 274 \\
\hline Letter search error & 0.9 & 2.6 & 1.1 & 3.2 & 1.9 & 3.5 & 1.6 & 3.5 \\
\hline $\begin{array}{l}\text { Lexical decision RT } \\
\text { Priming } \pm 95 \% \text { CI }\end{array}$ & 751 & 161 & \multicolumn{2}{|c|}{$0 \pm 20$} & \multicolumn{2}{|c|}{$11 \pm 19$} & \multicolumn{2}{|c|}{$37 \pm 18^{*}$} \\
\hline $\begin{array}{c}\text { Lexical decision error } \\
\text { Priming } \pm 95 \% \text { CI }\end{array}$ & 2.1 & 3.7 & $\begin{array}{l}1.1 \\
1.04 \pm\end{array}$ & $\begin{array}{r}2.8 \\
.01^{*}\end{array}$ & $-0.1 \pm 1.1$ & $\begin{array}{l}4.1 \\
1.1 \\
\end{array}$ & $\begin{array}{l}1.2 \\
0.9 \pm\end{array}$ & $\begin{array}{l}3.2 \\
.0^{\dagger}\end{array}$ \\
\hline
\end{tabular}

Note-Unrel, unrelated prime; Sem, semantically related prime; O/P, orthographically/ phonologically related prime; Sem $+\mathrm{O} / \mathrm{P}$, semantically and orthographically/phonologically related prime; $\mathrm{CI}$, confidence interval. ${ }^{*} p<.05$, two-tailed. $\quad{ }^{\dagger} p<.05$, one-tailed. 


\section{DISCUSSION}

As is typically found in the literature, LS on the prime eliminated both Sem priming (see Tse \& Neely, 2007, for a review) and $\mathrm{O} / \mathrm{P}$ priming (Ferguson \& Besner, 2006; Kahan et al., 2006) for RTs. Although Tse and Neely observed LS Sem priming for targets with word frequencies comparably low to those of the present targets, we conjecture that we did not obtain LS Sem priming here because the prime-target association strengths and semantic overlap were too low to produce a detectable LS Sem priming effect even with our low-frequency targets. However, because our LS Sem priming and O/P priming effects were both null we could still test between the extended morphological hypothesis and the summed activation hypothesis. Because boat and float do not share a morpheme, our finding of a robust 37-msec Sem $+\mathrm{O} / \mathrm{P}$ priming effect that was significantly greater than the sum of the null $0-\mathrm{msec}$ Sem and 11-msec O/P priming effects supports the summed activation hypothesis and disfavors the extended morphological hypothesis. Thus, the most parsimonious conclusion is that semantic and $\mathrm{O} / \mathrm{P}$ activation are automatic and not affected by LS and that semantic and $\mathrm{O} / \mathrm{P}$ activation levels that are too low to be detectable via their individual priming effects can be detected when they are combined. Although it is possible that the morphological priming previously observed after LS is due to a separate morphological representational level, the present findings show that it is not necessary to postulate a separate morphological representational level to explain why LS eliminates Sem and O/P priming but not morphological priming. Moreover, along with the results of Tse and Neely and others (Heil, Rolke, \& Pecchinenda, 2004; Hutchison \& Bosco, 2007; Marí-Beffa, Valdés, Cullen, Catena, \& Houghton, 2005), the present results also suggest that a null Sem priming effect for LS primes cannot be taken as compelling evidence for the claim that semantic activation is not automatic because LS depletes the attentional resources necessary for semantic activation to occur.

One potential limitation of our design is that it does not show that LS "eliminated" Sem priming and/or O/P priming, because we do not know whether these priming effects would have occurred had the prime been read silently. However, with the materials used here, Pastizzo (2003) found a significant 14-msec Sem priming effect and a nonsignificant $-6-\mathrm{msec} \mathrm{O} / \mathrm{P}$ priming effect from an unmasked silently read prime with a 250-msec SOA that likely would have eliminated strategic priming mechanisms, thereby leaving only activation to produce priming. Although we cannot conclude that $\mathrm{O} / \mathrm{P}$ priming was eliminated by LS (because it was null even when the prime was read silently in Pastizzo, 2003), our main conclusion does not change. Even though LS Sem priming was null $(0 \mathrm{msec})$, when it was combined with a statistically null 11-msec LS O/P priming effect, the result was a robust and significant $37-\mathrm{msec}$ priming effect. Thus, the conclusion remains that LS semantic activation detectably facilitated our significant Sem $+\mathrm{O} / \mathrm{P}$ priming effect, showing that LS does not eliminate semantic activation.
However, one could argue that semantic activation was indeed eliminated during LS and that our LS Sem $+\mathrm{O} / \mathrm{P}$ priming effect was produced by a retrospective priming mechanism that begins after the target is presented (e.g., Besner, Stolz, \& Holcomb, 2005). That is, perhaps the target's presentation reactivates the prime's semantic representation via a backward target-to-prime association. Such reactivation of the prime could in turn activate the target via a forward prime-to-target association, thereby producing priming even though semantic activation was completely eliminated during LS on the prime. This seems unlikely, given the very low backward- and forwardassociative strengths between the primes and targets in our Sem $+\mathrm{O} / \mathrm{P}$ priming condition and the fact that Tse and Neely (2007) found LS Sem priming for low-frequency targets when the backward, target-to-prime associative strength was $0.00 .{ }^{3}$ Moreover, this account fails to explain why Hutchison and Bosco (2007) and Marí-Beffa et al. (2005) found evidence for semantic activation during LS on a prime that failed to produce semantic priming.

Given these arguments, we believe that morphological priming may not be mediated by a separate, specialized morphemic representational level that is activated independently of semantic and phonological representations, as some (e.g., Brown et al., 2006; Marslen-Wilson et al., 1994; Rastle, Davis, Marslen-Wilson, \& Tyler, 2000) have argued. Our belief is supported by Rastle et al.'s (Experiment 2) finding (which our present results replicate) that $\mathrm{Sem}+\mathrm{O} / \mathrm{P}$ priming was greater by $18-22 \mathrm{msec}$ than the amount of priming expected on the basis of the sum of the separate magnitudes of Sem and $\mathrm{O} / \mathrm{P}$ priming in a shortSOA, masked-prime paradigm. (Feldman, 2000, and Pastizzo, 2003, have also reported that morphological and $\mathrm{Sem}+\mathrm{O} / \mathrm{P}$ priming effects, respectively, exceed the sum of separate Sem and $\mathrm{O} / \mathrm{P}$ priming effects.) However, because Rastle et al. also found that morphological priming was 27-29 msec greater than $\mathrm{Sem}+\mathrm{O} / \mathrm{P}$ priming when the primes and targets did not share a morpheme, they argued for a separate morphemic representational level distinct from the semantic and phonological representational levels. However, the summed activation hypothesis can also explain why morphologically related (marker-mark) pairs produce more priming than do boat-float type pairs because morphologically related pairs (typically) have much greater semantic overlap. The important point is that the summed activation hypothesis can account for the present findings in addition to those reported by Tse and Neely (2007), whereas the extended morphological hypothesis cannot.

Because morphologically related primes and targets are almost by necessity more related semantically than $\mathrm{Sem}+\mathrm{O} / \mathrm{P}$ primes and targets that do not share a morpheme, the crucial issue is not whether morphological priming is greater than $\mathrm{Sem}+\mathrm{O} / \mathrm{P}$ priming (which is why we did not include a morphological priming condition in the present experiment). Rather, the crucial issues become (1) whether Sem $+\mathrm{O} / \mathrm{P}$ priming is statistically greater than the sum of Sem and $\mathrm{O} / \mathrm{P}$ priming effects, regardless of whether or not the Sem $+\mathrm{O} / \mathrm{P}$ prime and target share a morpheme, and (2) whether morphological priming and 
Sem $+\mathrm{O} / \mathrm{P}$ priming effects are dissociated by the effects of another variable. By these two criteria, our data provide no evidence that morphological priming is anything other than summated Sem and O/P priming effects. That is, (1) our 37-msec Sem $+\mathrm{O} / \mathrm{P}$ priming effect for primes and targets that did not share a morpheme was statistically greater than the $11-\mathrm{msec}$ sum of the individual 0 -msec Sem and 11-msec O/P priming effects, and (2) although LS Sem and O/P priming effects were statistically null, LS Sem $+\mathrm{O} / \mathrm{P}$ priming still occurred as does LS morphological priming (Stolz \& Besner, 1998). Thus, until it is demonstrated that a variable has dissociative effects on $\mathrm{Sem}+\mathrm{O} / \mathrm{P}$ priming and morphological priming with materials as well controlled as those used here, we advocate a position of theoretical parsimony in which a separate morphemic representational level is not postulated.

\section{AUTHOR NOTE}

We thank Derek Besner, Laurie Feldman, Kathleen Rastle, and an anonymous reviewer for their comments on an earlier draft, and Jessica Beers, Renae Hesse, and Brooke Marley for their help with data collection. Address correspondence to M. J. Pastizzo, Psychology Department, SUNY Geneseo, 1 College Circle, Geneseo, NY 14454 (e-mail: pastizzo@geneseo.edu).

\section{REFERENCES}

Besner, D., Stolz, J. A., \& Holcomb, P. (2005). On the persisting myth of automatic semantic activation in visual word recognition: What N400 doesn't measure. Unpublished manuscript.

Brown, M. S., Roberts, M. A., \& Besner, D. (2001). Semantic processing in visual word recognition: Activation blocking and domain specificity. Psychonomic Bulletin \& Review, 8, 778-784.

Brown, M. [S.], Stolz, J. A., \& Besner, D. (2006). Dissociative effects of stimulus quality on semantic and morphological contexts in visual word recognition. Canadian Journal of Experimental Psychology, 60, 190-199.

Chiappe, P. R., Smith, M. C., \& Besner, D. (1996). Semantic priming in visual word recognition: Activation blocking and domains of processing. Psychonomic Bulletin \& Review, 3, 249-253.

Feldman, L. B. (2000). Are morphological effects distinguishable from the effects of shared meaning and shared form? Journal of Experimental Psychology: Learning, Memory, \& Cognition, 26, 1431-1444.

Ferguson, R., \& Besner, D. (2006). Basic processes in reading: Can functional phonological recoding be blocked? Canadian Journal of Experimental Psychology, 60, 148-158.

Heil, M., RolKe, B., \& PeCChINENdA, A. (2004). Automatic semantic activation is no myth: Semantic context effects on the N400 in the letter-search task in the absence of response time effects. Psychological Science, 15, 852-857.

Hutchison, K. A., \& Bosco, F. A. (2007). Congruency effects in the letter search task: Semantic activation in the absence of priming. Memory \& Cognition, 35, 514-525.

Kahan, T. A., Sellinger, J. J., \& Broman-Fulks, J. J. (2006). Associative and phonological priming effects after letter search on the prime. American Journal of Psychology, 119, 239-254.

KuČERA, H., \& FRANCIS, W. N. (1967). Computational analysis of presentday American English. Providence, RI: Brown University Press.

Landauer, T. K., \& Dumais, S. T. (1997). A solution to Plato's problem: The latent semantic analysis theory of acquisition, induction, and representation of knowledge. Psychological Review, 104, 211-240.

Marí-Beffa, P., Valdés, B., Cullen, D. J. D., Catena, A., \& HoughTON, G. (2005). ERP analyses of task effects on semantic processing from words. Cognitive Brain Research, 23, 293-305.

Marslen-Wilson, W. [D.], Tyler, L. K., Waksler, R., \& Older, L. (1994). Morphology and meaning in the English mental lexicon. Psychological Review, 101, 3-33.

McNamara, T. P. (2005). Semantic priming: Perspectives from memory and word recognition. New York: Psychology Press.
Neely, J. H. (1977). Semantic priming and retrieval from lexical memory: Roles of inhibitionless spreading activation and limitedcapacity attention. Journal of Experimental Psychology: General, 106, 226-254.

NeEly, J. H., \& Kahan, T. A. (2001). Is semantic activation automatic? A critical re-evaluation. In H. L. Roediger III, J. S. Nairne, I. Neath, \& A. M. Surprenant (Eds.), The nature of remembering: Essays in honor of Robert G. Crowder (pp. 69-93). Washington, DC: American Psychological Association.

Neely, J. H., \& Keefe, D. E. (1989). Semantic context effects on visual word processing: A hybrid prospective-retrospective processing theory. In G. H. Bower (Ed.), The psychology of learning and motivation: Advances in research and theory (Vol. 24, pp. 207-248). New York: Academic Press.

Neely, J. H., Keefe, D. E., \& Ross, K. L. (1989). Semantic priming in the lexical decision task: Roles of prospective prime-generated expectancies and retrospective semantic matching. Journal of Experimental Psychology: Learning, Memory, \& Cognition, 15, 1003-1019.

Nelson, D. L., McEvoy, C. L., \& Schreiber, T. A. (2004). The University of South Florida free association, rhyme, and word fragment norms. Behavior Research Methods, Instruments, \& Computers, 36, 402-407.

Pastizzo, M. J. (2003). Multiple dimensions of relatedness among words: Do effects of form and meaning interact? Unpublished doctoral dissertation, University at Albany, State University of New York.

Raaijmakers, J. G. W., Schrijnemakers, J. M. C., \& Gremmen, F. (1999). How to deal with "the language-as-fixed-effect fallacy": Common misconceptions and alternative solutions. Journal of Memory \& Language, 41, 416-426.

Rastle, K., Davis, M. H., Marslen-Wilson, W. D., \& Tyler, L. K. (2000). Morphological and semantic effects in visual word recognition: A time-course study. Language \& Cognitive Processes, 15, 507-537.

Stolz, J. A., \& BeSNER, D. (1998). Levels of representation in visual word recognition: A dissociation between morphological and semantic processing. Journal of Experimental Psychology: Human Perception \& Performance, 24, 1642-1655.

Stolz, J. A., \& Besner, D. (1999). On the myth of automatic semantic activation in reading. Current Directions in Psychological Science, 8, 61-65.

Tse, C.-S., \& NeELy, J. H. (2007). Semantic priming from letter-searched primes occurs for low- but not high-frequency targets: Automatic semantic access may not be a myth. Journal of Experimental Psychology: Learning, Memory, \& Cognition, 33, 1143-1161.

\section{NOTES}

1. The prediction that $\mathrm{Sem}+\mathrm{O} / \mathrm{P}$ priming will be overadditive with respect to the separate Sem and $\mathrm{O} / \mathrm{P}$ priming effects does not depend on $\mathrm{Sem}+\mathrm{O} / \mathrm{P}$ activation's being overadditive with respect to the separate $\mathrm{Sem}$ and $\mathrm{O} / \mathrm{P}$ activation levels. That is, overadditive $\mathrm{Sem}+\mathrm{O} / \mathrm{P}$ priming would occur because the individual Sem and $\mathrm{O} / \mathrm{P}$ activation levels are below the threshold level of activation necessary to produce a detectable priming effect whereas their additive (or even underadditive) sum would exceed this threshold.

2. According to Raaijmakers, Schrijnemakers, and Gremmen (1999), there is no need to perform item analyses on our data because the item variability was "controlled" by our counterbalancing scheme.

3 . Another possibility is that it was the $\mathrm{O} / \mathrm{P}$ similarity between the target and prime, rather than a backward association, that led to the target's reactivating the prime. This could produce $\mathrm{Sem}+\mathrm{O} / \mathrm{P}$ priming but not $\mathrm{O} / \mathrm{P}$ priming if $\mathrm{O} / \mathrm{P}$ priming does not occur for our materials and procedures. However, this explanation fails to account for why Tse and Neely (2007) were able to find LS Sem priming for low-frequency targets when there was no $\mathrm{O} / \mathrm{P}$ similarity between the target and prime. Moreover, if it is $\mathrm{O} / \mathrm{P}$ target-prime similarity that mediates prime reactivation, morphological priming from LS primes could be produced in the same way, which would also undermine Stolz and Besner's (1998) claim that morphological priming is based on activation that occurs in separate morphemic representations and that it is not affected by LS.

(Manuscript received August 10, 2007; revision accepted for publication February 11, 2008.) 